Supporting Information for Publication:

\title{
A Novel Synthesis Strategy for Biocatalyst: Fast Purification and Immobilization of His- and ELP-Tagged Enzyme from Fermentation Broth
}

Man Zhao, ${ }^{a}$ Junhui Rong, ${ }^{a}$ Juan Han, ${ }^{b}$ Yang Zhou, ${ }^{c}$ Chunmei Li, ${ }^{a}$ Lei Wang, ${ }^{a}$ Yanli Mao, ${ }^{d}$ Yun

$$
\text { Wang*a }
$$

a. School of Chemistry and Chemical Engineering, Jiangsu University, Zhenjiang, Jiangsu

Province, 212013, China.

b. School of Food and Biological Engineering, Jiangsu University, Zhenjiang, Jiangsu Province,

$$
\text { 212013, China. }
$$

c. Institute of Life Science, Jiangsu University, Zhenjiang, Jiangsu Province, 212013, China.

d. Henan Province Key Laboratory of Water Pollution Control and Rehabilitation Technology, Henan University of Urban Construction, Pingdingshan, Henan Province, 467036, China

* Corresponding author. Tel.: +86 0511 88790683; Fax.: +86 0511 88791800;

E-mail: yunwang@ujs.edu.cn (Yun Wang) 


\section{EXPERIMENTAL SECTION}

Purification of Fusion Protein. First, $0.99 \mathrm{~g}\left(\mathrm{NH}_{4}\right)_{2} \mathrm{SO}_{4}$ was added into $1.5 \mathrm{~mL}$ crude extract, and the mixture was centrifuged at $14,000 \times g$ after incubating at $25^{\circ} \mathrm{C}$ for 10 minutes. Then, the cold Tris- $\mathrm{HCl}$ buffer $(50 \mathrm{mM}, \mathrm{pH} 8.0)$ was added into the precipitate and the obtained suspension was centrifuged at $14,000 \times g$ after incubated at $4{ }^{\circ} \mathrm{C}$. Finally, the supernatant was moved into a new centrifuge tube for next step and the remaining precipitates were resuspended with Tris- $\mathrm{HCl}$ buffer (50 mM, pH 8.0).

Characterization of Hybrid GLEH-NF. The scanning electron microscopy (SEM) and energy-dispersive X-ray spectroscopy (EDS) of the resultant hybrid nanoflowers was recorded on a JSM-6010LA scanning electron microscope (JEOL, Japan). The absorbance data were obtained by using a multiskan spectrum microplate spectrophotometer (Synergy H1, BioTek Instruments, Inc., USA). The crystalline morphology of hybrid GLEH-NF were determined through X-ray powder diffraction (XRD) (XRD-6100, Shimadzu, Japan). The Fourier transform infrared (FT-IR) spectra of GLEH-NF were carried out with a FT-IR spectrophotometer (Nexus, Thermo Nicolet, USA). The surface area and pore size of the nanoflowers were analyzed by Brunauer-Emmett-Teller (BET) and Barrett-Joyner-Halenda (BJH) methods using a NOVA2000 physisorption analyzer (Quantachrome Instruments, USA). The particle diameter distribution (PDD) range of nanoflowers was determined with a particle size analyzer (Mastersizer 3000, Malvern Instruments Ltd., UK). The thermogravimetric analysis (TGA) 
curves of the hybrid nanoflowers was performed with Netzsch STA449C thermal analyser (Germany).

Enzyme Activity Assays. The enzyme activity was measured though the amount of $p$-nitrophenol ( $p$-NP) decomposed from $p$-nitrophenyl- $\beta$-D-glucopyranoside ( $p$-NPG). The mixed solution of $40 \mu \mathrm{L} p$-NPG $(50 \mathrm{mM})$ and $450 \mu \mathrm{L}$ acetic acid-sodium acetate buffer $(50 \mathrm{mM}, \mathrm{pH}$ 5.5) was preheated in a water bath at $40{ }^{\circ} \mathrm{C}$ for $10 \mathrm{~min}$. Then, $10 \mu \mathrm{L}$ enzyme solution was added into the preheated mixture quickly and the heat preservation reaction was lasted for $10 \mathrm{~min}$. The reaction was terminated by adding $500 \mu \mathrm{L} \mathrm{Na}_{2} \mathrm{CO}_{3}(1 \mathrm{M})$. The enzyme activity was calculated by determining the absorbance of reaction solution at $410 \mathrm{~nm}$. The specific activity (U) of enzyme was defined as the amount of product produced by the catalytic reaction for one min.

Measurement of Kinetic Parameters. The kinetic parameters $\left(K_{\mathrm{m}}\right.$ and $\left.V_{\max }\right)$ of free enzyme and GLEH-NF were determined by measuring the enzyme activity using $p$-NPG as substrate at various concentrations ranging from 0.5 to $14 \mathrm{mM}$. The $K_{\mathrm{m}}$ and $V_{\max }$ values were calculated by the classical Lineweaver-Burk equation as follows.

$$
\frac{1}{V}=\frac{K_{m}}{V_{\max }} \times \frac{1}{[S]}+\frac{1}{V_{\max }}
$$

Where $V$ is the initial reactive rate $\left(\mathrm{mM} \mathrm{min}^{-1}\right), V_{\max }$ is the maximal reaction rate $(\mathrm{mM} \mathrm{min}-1$ $\left.\mathrm{mg}^{-1}\right),[S]$ is the initial $p$-NPG concentration, and $K_{\mathrm{m}}$ is the Michaelis - Menten constant (mM). 


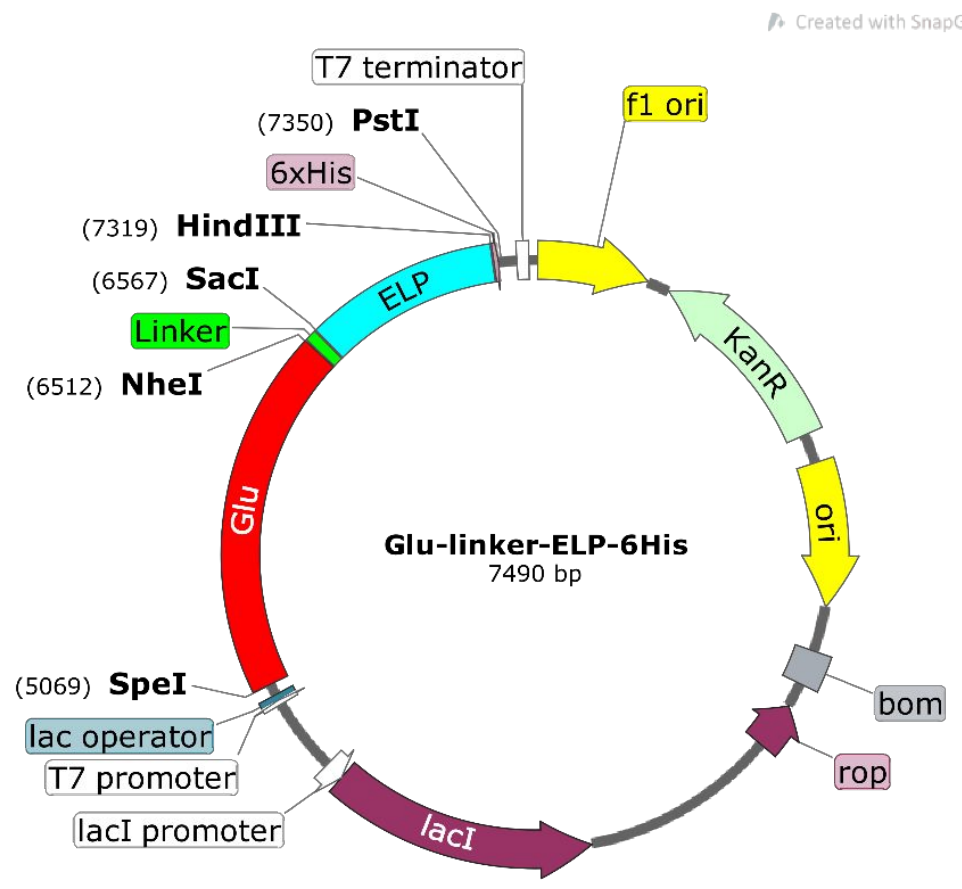

Figure S1. Schematic diagram of recombinant plasmid pET-GLEH. The length of gene encoding linker, ELP and 6His are 45, 750 and 18 bp, respectively. The Glu gene was cloned into the SpeI and NheI sites, and the ELP-6His sequence was fused to the C-terminal of Glu with the universal linker $(\mathrm{GGGGS})_{3}$. 


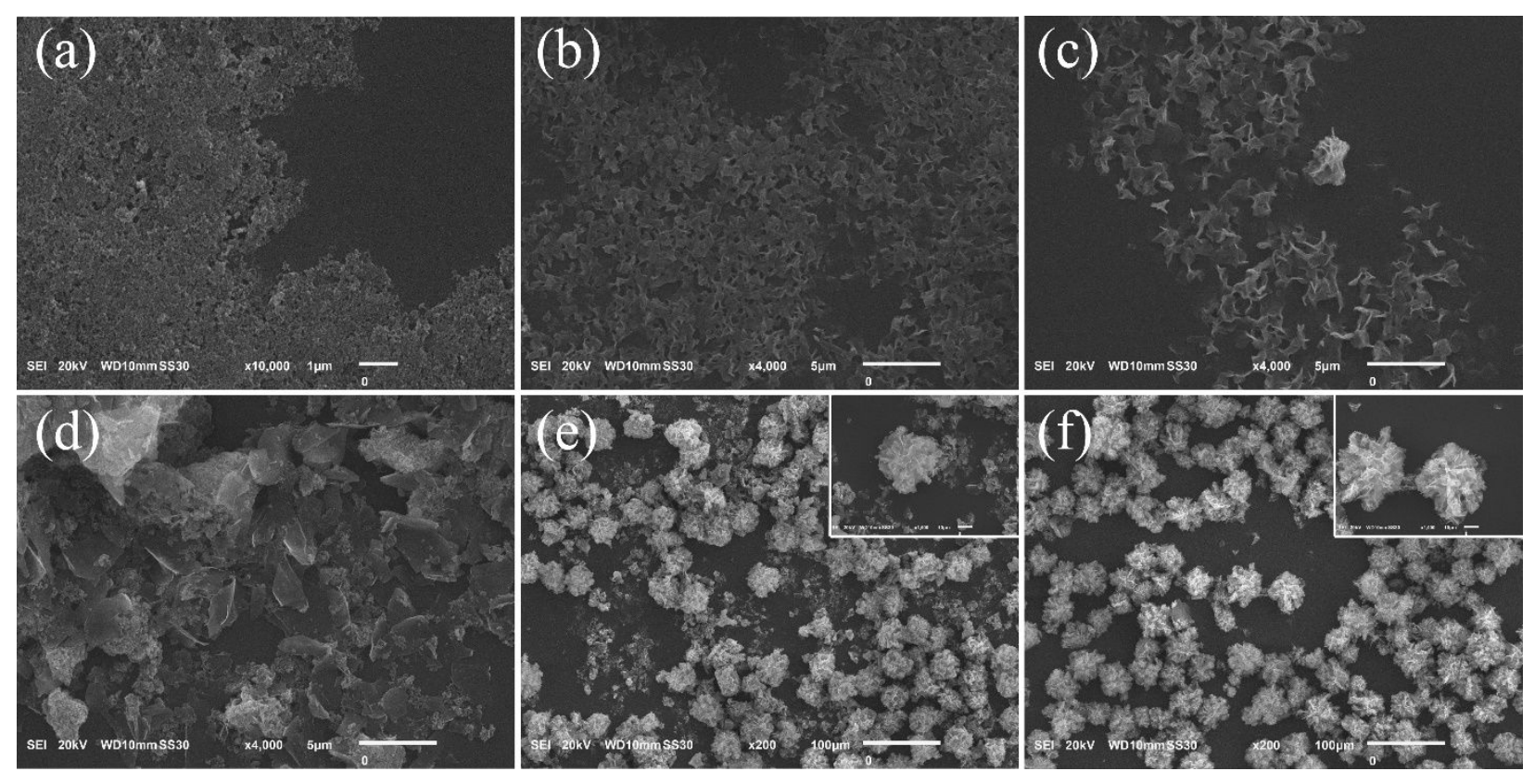

Figure S2. Effect of different incubation time on the morphologies of the nanoflowers in the absence of GLEH. (a) $10 \mathrm{~min}$; (b) $30 \mathrm{~min}$; (c) $1 \mathrm{~h}$; (d) $2 \mathrm{~h}$; (e) $3 \mathrm{~h}$; (f) $4 \mathrm{~h}$; Other conditions: 4.8 $\mathrm{mM} \mathrm{Cu}^{2+}, 10 \mathrm{mM}$ PBS at $\mathrm{pH}=7.4$, and reaction at $25^{\circ} \mathrm{C}$. 

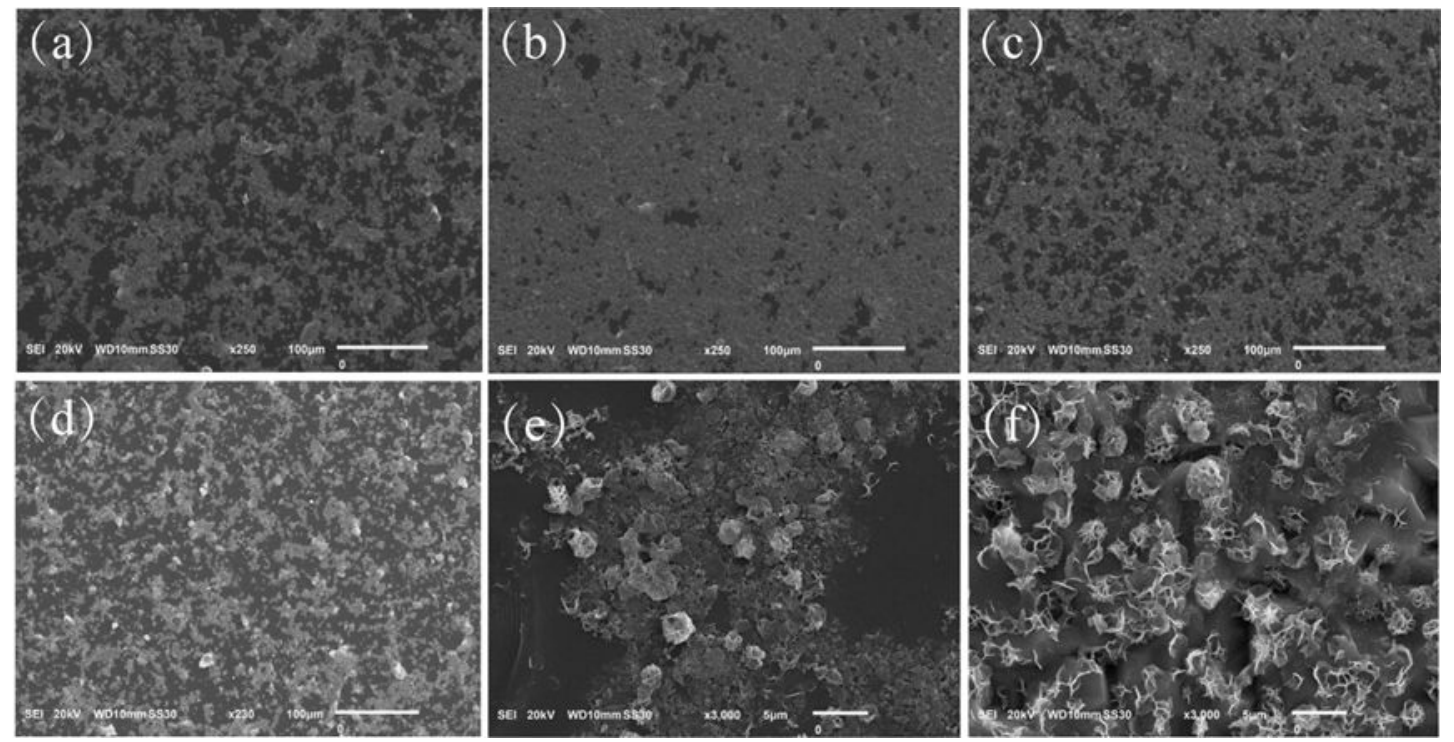

Figure S3. Effect of different incubation time on the morphologies of the hybrid nanoflowers.

(a) $10 \mathrm{~min}$; (b) $30 \mathrm{~min}$; (c) $1 \mathrm{~h}$; (d) $2 \mathrm{~h}$; (e) $3 \mathrm{~h}$; (f) $4 \mathrm{~h}$; Other conditions: $2.4 \mathrm{mM} \mathrm{Cu}^{2+}, 50 \mu \mathrm{g} / \mathrm{mL}$ GLEH, $10 \mathrm{mM}$ PBS at $\mathrm{pH}=7.4$, and reaction at $25^{\circ} \mathrm{C}$. 

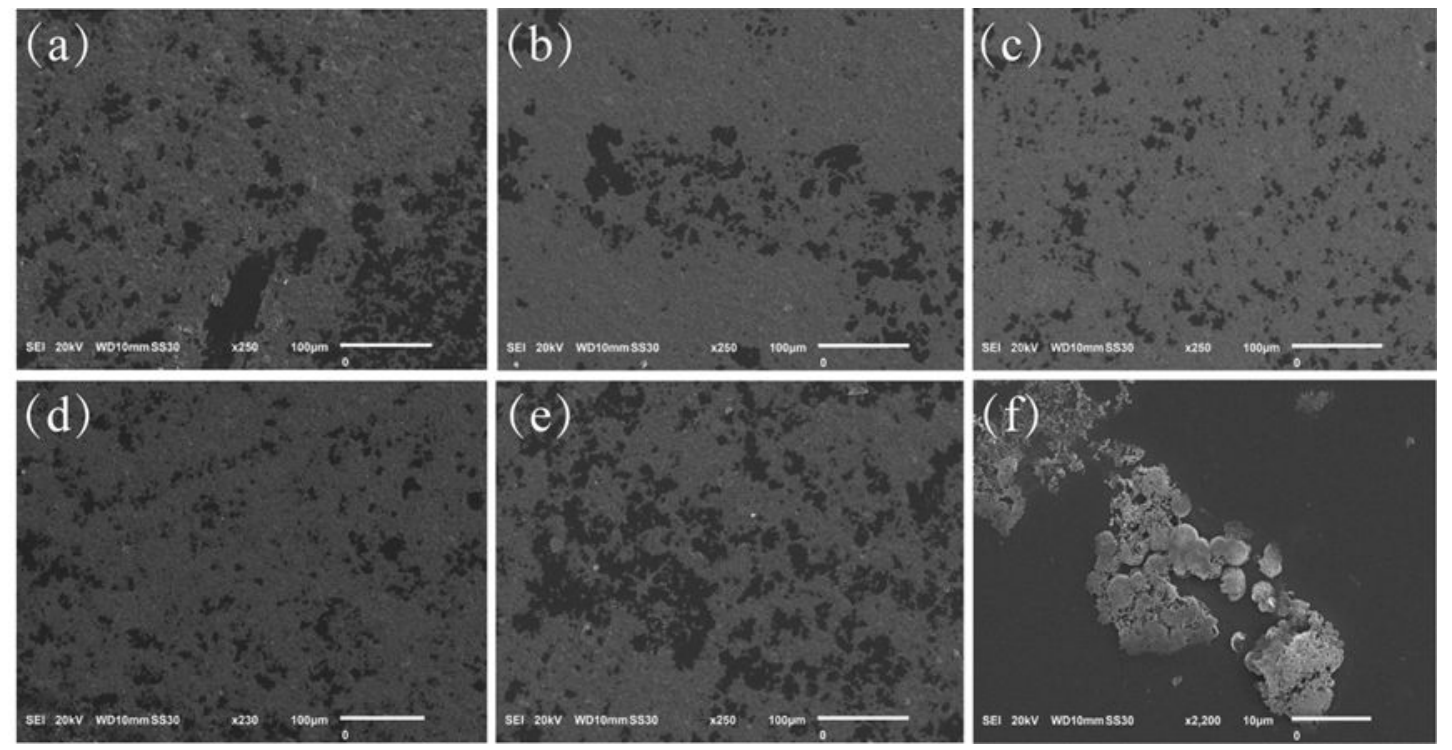

Figure S4. Effect of different incubation time on the morphologies of the nanoflowers in the absence of GLEH. (a) $10 \mathrm{~min}$; (b) $30 \mathrm{~min}$; (c) $1 \mathrm{~h}$; (d) $2 \mathrm{~h}$; (e) $3 \mathrm{~h}$; (f) $4 \mathrm{~h}$; Other conditions: 2.4 $\mathrm{mM} \mathrm{Cu}{ }^{2+}, 10 \mathrm{mM}$ PBS at $\mathrm{pH}=7.4$, and reaction at $25^{\circ} \mathrm{C}$. 

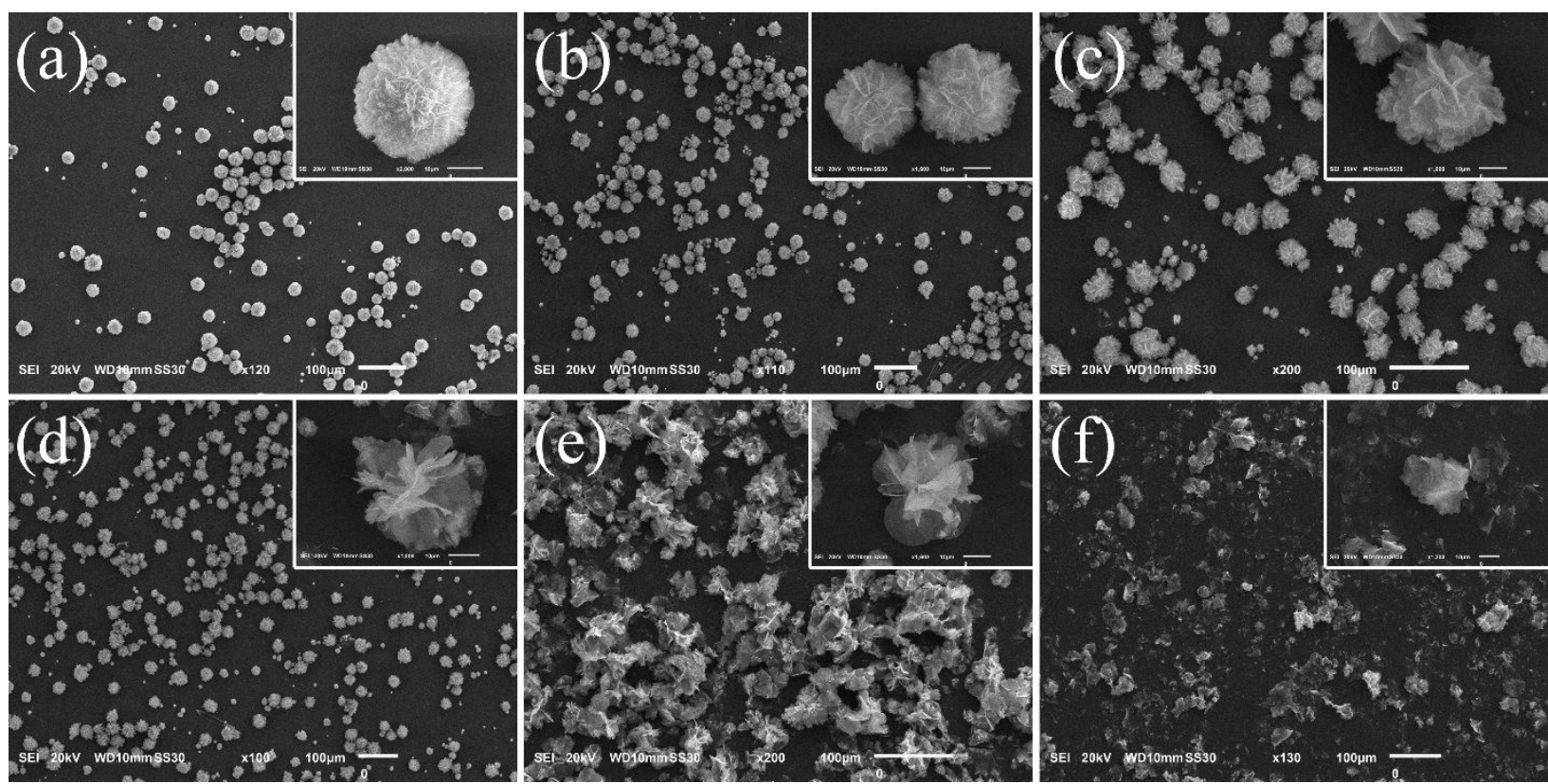

Figure S5. Effect of different temperature on the morphologies of the hybrid nanoflowers. (a) 4

${ }^{\circ} \mathrm{C}$; (b) $15{ }^{\circ} \mathrm{C}$; (c) $25{ }^{\circ} \mathrm{C}$; (d) $35^{\circ} \mathrm{C}$; (e) $45^{\circ} \mathrm{C}$; (f) $55^{\circ} \mathrm{C}$; Other conditions: $4.8 \mathrm{mM} \mathrm{Cu}{ }^{2+}, 50$

$\mu \mathrm{g} / \mathrm{mL}$ GLEH, $10 \mathrm{mM}$ PBS at $\mathrm{pH}=7.4$, and reaction for $24 \mathrm{~h}$. 
(a)
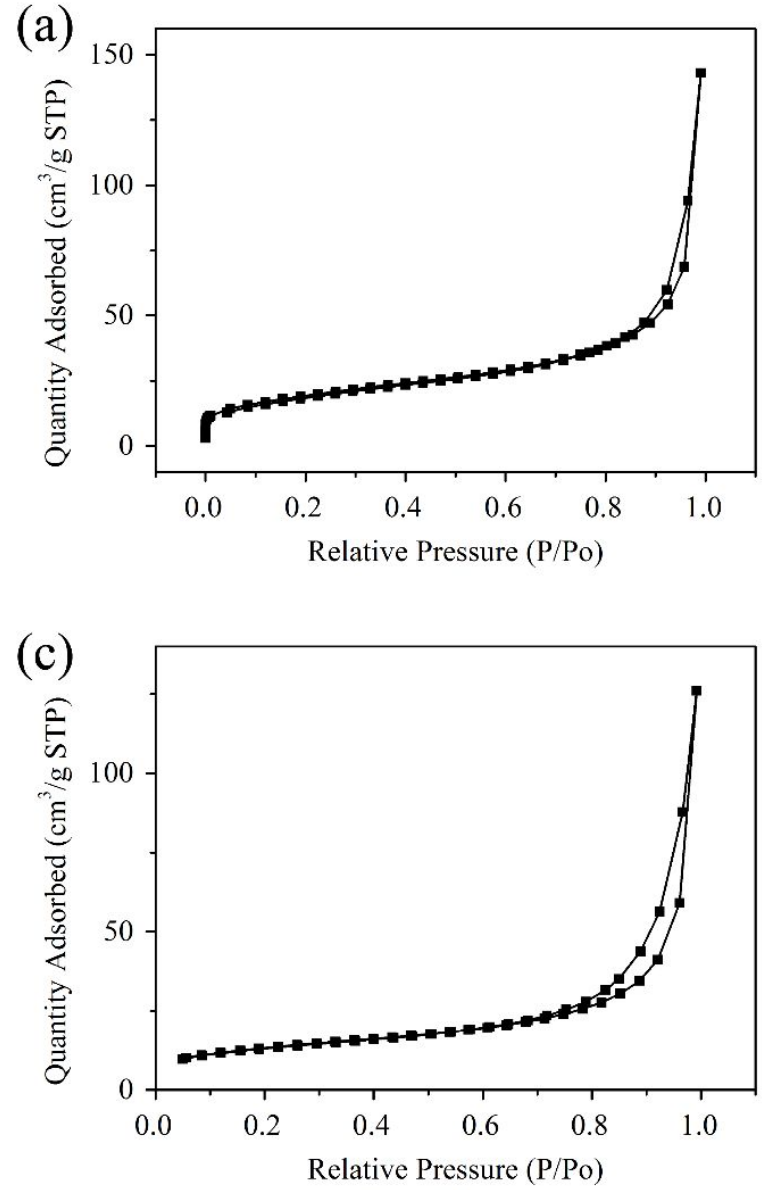
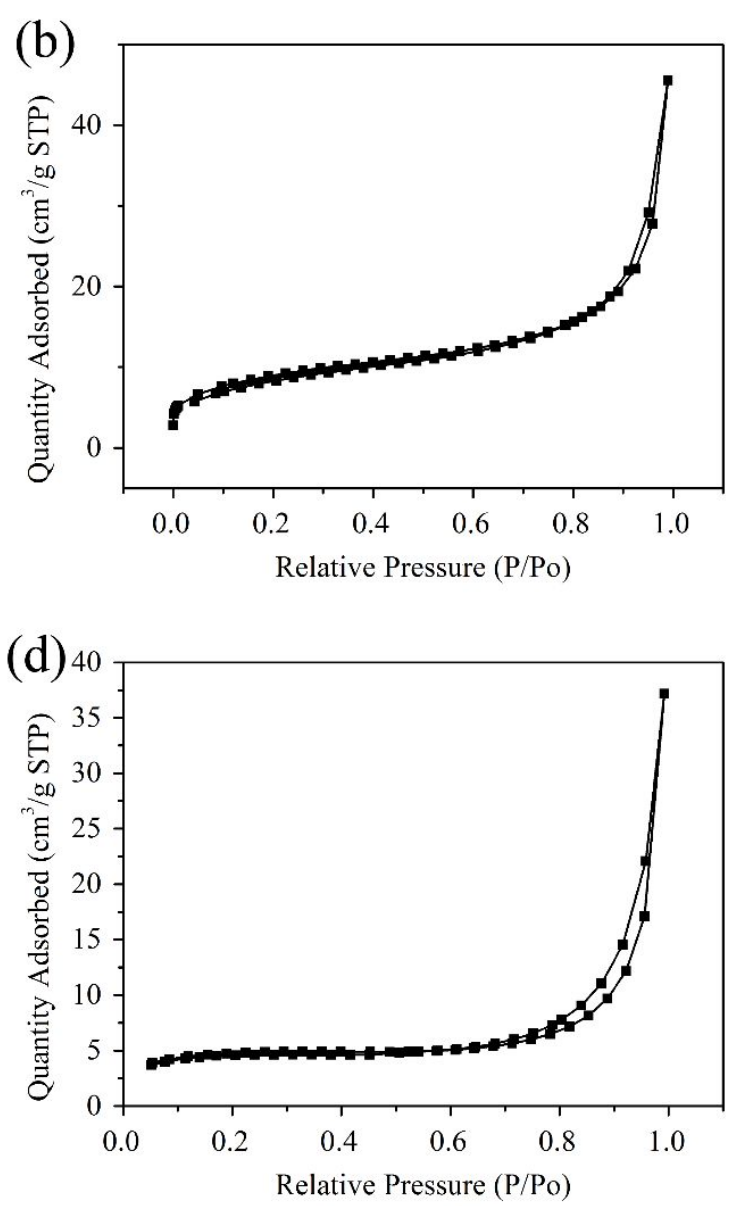

Figure S6. $\mathrm{N}_{2}$ adsorption-desorption isotherms curves of nanoflowers prepared under different conditions: $\mathrm{Cu}_{2}\left(\mathrm{PO}_{4}\right)_{3}$ synthesized at 4 (a) and $25{ }^{\circ} \mathrm{C}(\mathrm{b})$; GLEH-NF synthesized at $4{ }^{\circ} \mathrm{C}(\mathrm{c})$ and $25^{\circ} \mathrm{C}(\mathrm{d})$. 